NorE.-In sixteen of the alloys investigated a transformation point was noted (in addition to the three freezing points) at a fixed temperature, approximately $124^{\circ}$. In every instance observed the transformation took place below the temperature at which binary eltectic had begun freezing. The phenomenon was not noticed early in the investigation, and the data at hand are not sufficient to enable me to fix the limits of composition within which the change takes place. If the halt is caused by the formation in the partly-solid alloy of a binary or ternary compound, the extent to which this compound may form mix-crystals with the three pure metals will decide whether it is necessary to introduce another surface-roughly triangular in outline-at the point now assigned to the ternary eutectic. I intend to resume the investigation of the transformation at an early date, and ask for a reasonable time reservation for this purpose.

Metallergical Laboratory, Virginia polytechic institute, BLACKSBURG, VA.

[CONtribution from the Laboratories of General and Physical Chemistry of THE UNIVERSITY OF CHICAGO.]

\title{
STUDIES IN VAPOR PRESSURE: III. A STATIC METHOD FOR DETERMINING THE VAPOR PRESSURES OF SOLIDS AND LIQUIDS. ${ }^{1}$
}

\author{
By Alexander SMith aNd Alan $W$. C. Menzizs.
}

Received August 20, I910.

This paper consists of five sections dealing, respectively, with:

(I) The sources of error of a more general character involved in vapor pressure measurement.

(2) A critical résumé of the characteristics of the older methods, with particular reference to the individual sources of error in each.

(3) A description of the present apparatus.

(4) A criticism of this apparatus, in relation to the various sources of error.

(5) A set of measurements of the vapor pressures of water, made with a view to testing the efficiency of the apparatus.

The apparatus was applied in a redetermination of the vapor pressure of mercury, and in a quantitative study of the chemical constitution of calomel vapor, which will be described in separate papers.

\section{Section I. General Sources of Error Involved in Vapor Pressure Measurement.}

A critical study of the very voluminous literature of vapor pressures reveals the fact that, where two or more independent series of values for the same substance are in existence, inconsistency is the rule and substantial quantitative agreement throughout two comparable series the exception. The differences range from a few tenths of a millimeter

1 This paper, and the two following, were read at the Boston meeting of the Society, on Dec. 3०, I 909. 
to several hundred millimeters. ${ }^{1}$ In view of this discordance, which affects also our own results when they are compared with those of others, some space must be taken to discuss the general sources of error in the measurement of vapor pressure and to give some account of the older methods. The aim of this discussion is to attempt to indicate the precise conditions that must be met if these chief sources of error are to be avoided. When the sources of error have thus been defined, it is possible to show how far the method described in this paper meets the required conditions, and how far confidence may be placed in the experimental results secured by its means.

The sources of errors that are common to most methods of vapor pressure determination may, perhaps, be best discussed under the three heads of temperature, pressure, and impurity of material:

Temperature.-(I) Steadiness and Equal Distribution.-When the condensing vapor from a liquid boiling in a flask is used to maintain a steady temperature, the vapor, at first inevitably superheated, is expected to cool itself to the boiling point by radiation and by giving up heat to the bodies that it encounters. If the latter are too thoroughly jacketed, they may not lose the heat sufficiently fast to cool to the boiling point the vapor in the neighborhood of the thermometer. Errors, therefore, arise when the boiling is rapid, or when a sand bath or other large radiating surface is used as a source of heat. With inadequate jacketing, on the other hand, the latent heat of the vapor may be insuffcient to raise the temperature of the heated bodies to the boiling point. This is a common experience, for example, in determining the sulphur boiling point of a platinum thermometer. In this connection it has not always been borne in mind that the latent heat of evaporation of water is exceptionally high, that of other liquids having, at their boiling points, only a fraction of the value for water. Again, when the liquid is boiled under reduced pressure, ${ }^{2}$ the mass of vapor condensing is necessarily smaller, and its heating power, in virtue of latent heat, much less. It will be seen that, for a steam jacket, a much greater latitude in strength of heating (e. g., of flame-height) is possible than for other jacketing vapors.

Liquid baths, having a large volume and therefore a large heat capacity, have generally been found satisfactory in maintaining steady temperatures whenever the stirring was adequate (see Section 3, below), which, however, has not always been the case. Air baths, on account of their small heat capacity, are far inferior, ${ }^{3}$ and when employed have frequently not been stirred at all.

'See Landolt and Börnstein's, or any similar set of tables.

2 As in Ramsay and Young's method of securing any desired temperature from $0^{\circ}$ to $360^{\circ}$, by use of eight liquids ( $J$. Chem. Soc., 47, 640; 55, 483).

See, e. g., this series, No. V, following. 
(2) Accurate Determination of Actual Temperature.-Explicit statements of the method of standardization of the thermometers used and of the degree of probable accuracy in the measurement of temperature are frequently wanting. In mercurial thermometry, it may be mentioned, the correction for external pressure upon the bulb is very uniformly omitted (see Section 2, below); too much faith is placed in an arithmetical correction for "exposed thread;" and readings to tenths above $300^{\circ}$ are treated with too much respect.

(3) Scale of Temperature.-In few cases is the scale specified or, apparently, considered. Since even so low as $200^{\circ}$ the difference between the constant-pressure air scale and the thermodynamic scale is of the order of $0.1^{\circ}$ (corresponding to a pressure difference of several $\mathrm{mm}$.), and at $45^{\circ}$ the difference is nearly $0.5^{\circ}$, it would appear that many refinements in measuring or calculating pressures to single millimeters, not to speak of tenths, hundredths, and even thousandths of a mm. that are found in the literature, are really superfluous.

As a sample of vapor pressure thermometry, similar to dozens that might be cited, the determination of the vapor pressures of iodine by $\mathrm{E}$. Wiedemann ${ }^{1}$ may be mentioned. At $180^{\circ}$, for example, he found the value $687.2 \mathrm{~mm}$. Since he says nothing about the style of the thermometer, about corrections, or about the scale of temperature referred to, two of these figures in the pressure are without significance. It is not remarkable, therefore, that the value is $25 \mathrm{~mm}$. (corresponding to nearly I. $5^{\circ}$ ) divergent from that of Ramsay and Young, ${ }^{2}$ and that his results add absolutely nothing to our previous knowledge.

Pressure. - The straightforward reduction of gage and barometer readings to $\mathrm{mm}$. of mercury at $0^{\circ}$ is not always stated to have been performed. Correction is made for the varying value of the gravity constant $(g)$ only in very exceptional cases. Yet, in Chicago, a place not very elevated, and not far from $45^{\circ} \mathrm{N}$. $\mathrm{L}_{\text {.., }}$ this correction amounts to 0.25 $\mathrm{mm}$. per $760 \mathrm{~mm}$., and in laboratories in London the value is about 0.5 mm. per atmosphere. This correction, therefore, usually considerably exceeds the error involved in the mere reading of the gage.

Impurity.--In the matter of purifying the crude material for the purposes of vapor pressure measurement, the physicist is usually admittedly at a disadvantage. But here even the chemist may be found somewhat unintelligently distilling "nine times" or freezing out or recrystallizing "fifteen times", with no guarantee that any increase of purity is being attained. How real is the necessity for purification may be judged from the statement of Tammann ${ }^{3}$ that 0.0 I per cent. of alcohol in benzene

1 Ber. physik. Ges., 3, I59 (1905).

$2 \mathrm{~J}$. Chem. Soc., 49, 453 (1886).

${ }^{3}$ Ann. Physik, [3] 32, 683 (1887). 
raised the vapor pressure of the latter, near the boiling point, by $12 \mathrm{~mm}$.

A somewhat different class of impurity is met with in the moisture, oxygen, nitrogen and carbon dioxide dissolved in liquids or adhering to solid substances. Such impurities form undoubtedly a most constant and elusive source of error. The seriousness of the error due to this cause, however, varies much with the particular method employed. Attention may, perhaps, here be called to a fact which seems to be very generally overlooked, namely, that gases are, as a rule, much more soluble in other liquids than in water, and therefore, in general, have in other liquids more effective vapor pressure, and are less quickly and easily removed by boiling and other precautions than in the case of water. In the following table ${ }^{1}$ the solubilities of three common gases are stated as volumes of gas held in solution by one volume of various liquids under ordinary conditions.

\begin{tabular}{|c|c|c|c|}
\hline Iiquid. & 1 dioxide, $25^{\circ}$. & Nitrogen, $25^{\circ}$. & Oxygen, $20^{\circ}$. \\
\hline 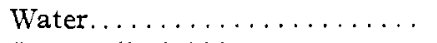 & 0.83 & 0.016 & 0.028 \\
\hline Carbon disulphide .......... & 0.87 & 0.059 & $\ldots$ \\
\hline Benzene. . . . . . . . . . . . . & 2.43 & O.II6 & $\ldots$ \\
\hline 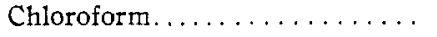 & $3 \cdot 43$ & 0.135 & $\ldots$ \\
\hline Methyl alcohol............. & 3.84 & o. $14^{2}$ & $\ldots$ \\
\hline Acetic acid............. & 4.68 & o.IIg & $\ldots$ \\
\hline Amyl acetate.......... & $4 \cdot 12$ & 0.173 & . . \\
\hline 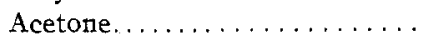 & 6.29 & o. I46 & $\ldots$ \\
\hline Alcohol $\ldots \ldots \ldots \ldots \ldots \ldots$ & $\ldots$ & $\ldots$ & 0.284 \\
\hline Petroleum.............. & I. I $7\left(20^{\circ}\right)$ & $0 . \operatorname{II7}\left(20^{\circ}\right)$ & 0.202 \\
\hline
\end{tabular}

It may be pointed out in this connection that there is, probably partly for this reason, far. less inconsistency in vapor pressure measurements of different observers in the case of water than in that of any other liquid. In many vapor pressure determinations there is no record of even an attempt to remove gases by preliminary boiling. Other observers boil for "two minutes" or for "some time." Not one of the widely used static methods admits of repetition of the boiling-out process till constant results are obtained, and thus the only sure proof of the effectiveness of the attempt to remove impurities is lacking" (see Section 2).

\section{Section 2. The Older Methods.}

Only certain methods will be here considered which are applicable over wide ranges of temperature, no mention being made of the tensi-

1 These figures are mainly from Just, Z. physik. Chem., 37, 354.

2 A re-opening of the apparatus and repetition of the boiling out, or some equivalent process, so far as we have noticed, is mentioned only as follows: Ramsay and Young, Phil. Trans., 177, 9I (I888), part of the observations with a single substance ( $\mathrm{NH}_{4} \mathrm{Cl}$ ) only. Lescoeur, Ann. chim. phys., [6] 16, 389 (1889). Beckmann, $Z$, physik. Chem., 4, 534; Raoult, Ann. chim. phys., [6] 20, 30r (1890), liquid boiled, but not the mercury; method not applicable above I atm. Vanstone, $J$. Chem. Soc., 97, 429 (I9I0). 
metric, gas-current, dew-point, and other methods of limited range. Regnault's classification of methods into "static" and "dynamic" may be followed.

Static Methods.-As representing a large class of static methods, may be taken that form in which the substance is introduced into the Torricellian vacuum of a jacketed barometer tube. A special temperature error incident to this method arises from the difficulty of adequately stirring a tall bath of liquid, such as those used by several of the French investigators. The difficulties when the vapor of a boiling liquid is used for heating have been discussed already. The pressure measurement is naturally uncertain in those cases, which are by far the majority, where every part of the mercury column is not held at the same temperature as the vapor chamber.

But the chief source of error in this form of the static method lies in the impurity of the substance. In the first place, mercury vapor may be present as an impurity. We find Ramsay and Young at one time applying the correction for complete saturation of the vapor chamber with mercury vapor, while, under other circumstances, Young assumes the entire absence of mercury vapor. If the correction be made, its value, at least above $280^{\circ}$, has hither to been uncertain. Far more serious, however, is the uncertainty as to the inclusion with the substance of gases and moisture from the air, absorbed or dissolved in the solid or liquid, or adhering to the walls of the tube. Some observers attempt merely so to fill the tube with mercury that visible bubbles are absent. In such cases large amounts of absorbed gases must be liberated when the heating begins. Even with thorough boiling out; visible bubbles (not to speak of absorbed and invisible gases) may remain. ${ }^{1}$ To remove gaseous impurities, the most careful workers, for example, Ramsay and Young, ${ }^{2}$ boil, first the mercury and then the substance, in the barometer tube before inverting the latter. But even in such cases, save for the few exceptions mentioned in Section I, a repetition of the boiling out, to test the success of the procedure, has nerer been attempted. What would the chemist say of a gravimetric method in which heating to constant weight played no part? The adhesion of the liquid to the top of the barometer tube, frequently cited, is, no doubt, evidence against the presence of free "air," but hardly excludes the presence of dissolved and absorbed "air." It may be questioned, also, whether obtaining almost identical pressures with varying volumes of liquid and vapor is

1. Tammann, in a piece of work on the effects of small amounts of impurities (l.c.), boiled out thoroughly, and remarks that after this treatment there was "usually no air-bubble" in the tube.

${ }^{2}$ Phil. Trans., 175, 461 (1884). Young, Stoichiometry, I3I. 
a proof of the absence of foreign matter. ${ }^{1}$ At all events, Ramsay and Young's method, the results of which usually were satisfactory when judged by those two criteria, happened to be tested in a different way in a single instance. ${ }^{2}$ This tube was filled with mercury, which was thoroughly boiled in the tube as usual. Without the introduction of any substance, however, this tube was heated at 280 . I ${ }^{\circ}$, as for a determination. When the tube had cooled, a permanent gas was found to have accumulated. Calculation showed that, while the tube was at 280 . $1^{\circ}$, this gas must have exercised a partial pressure of $2.9 \mathrm{~mm}$. A second heating, if attempted, might have resulted in an increase in the amount of this gas. If a substance had been added, the amount of foreign gas could only have been still further augmented, so there is no assurance that these two tests are sensitive within $\pm 3-5 \mathrm{~mm}$. of foreign gas. Ramsay and Young's results are probably not subject to a systematic error, on account of filling, of such dimensions as this, but their exactness is due rather to the skill of the experimenters than to an inevitable accuracy inherent in the method.

The U-form apparatus, used by some investigators instead of a straight barometer tube, and applicable especially to pressures over one atmosphere, is open to very similar sources of error. Of quite another type is the static method in which pressure is measured by means of the Ladenburg spiral gage. ${ }^{8}$ Here again, however, what is chiefly to be desired is a procedure which will permit of repetition of the boiling-out process until constant results are obtained.

If an individual observer with a constant personal equation has difficulty in duplicating results by the static method, it is not to be wondered at that different observers differ among themselves. Take, for example, the vapor pressures of acetic acid at $100^{\circ}$, all as measured by the static method: Landolt $408.5 \mathrm{~mm}$., Ramsay and Young $4 \mathrm{r} 7 \mathrm{~mm}$., Wüllner $473 \mathrm{~mm}$; those of butyric acid at $20.3^{\circ}$ : Landolt $7.3 \mathrm{~mm}$., Ramsay and Young $0.35 \mathrm{~mm}$.

Not the least of the objections to the static method is the almost unbearable laboriousness of work which attempts to be accurate. Schmidt, ${ }^{4}$ after enumerating its difficulties, including one not noted by other observers, namely that a number of barometer tubes had to be rejected before one was found in which the pressures with small amounts of ?vapor were not larger than with greater amounts, adds: "The static method

1 Young, $J$. Chem. Soc., 55, 486 (I889). Abnormalities when the proportion of the liquid phase is exceedingly minute have indeed been observed (Wüllner and Grotian, Ann. Physik, [3] I I, 545; see also Ramsay and Young, Phil. Trans., I83, I07).

2 Phil. Trans., I77, 87 (1886).

Z. physik. Chem., 6r, 458; also Ibid., 68, I29. See No. V of this series.

I Z. physik. Chem., 8, 629 . 
has so many disadvantages, when compared with the dynamic, that I can only warn [observers] not to use it."

Dynamic Methods.--A simple form of the dynamic method consists in using a thermometer immersed in the vapor rising from a liquid boiling under various known pressures. So, for example, Regnault obtained his vapor pressure curve for sulphur, and Holborn and Henning their data for water. It is plain that such a method escapes the errors due to gaseous impurity, whether adhering or dissolved, and herein lies its chief advantage over the static methods. If a reflux condenser be employed, moisture and condensable volatil impurities do not escape; while if the vapor is condensed in another vessel, the less volatil impurities become concentrated in the residual liquid. In either case, if the current of vapor streaming into the condenser be a rapid one, the pressure within the flask is commonly slightly higher than the pressure at the distant end of the condenser with which the manometer is connected. Irregular boiling may cause large errors, and is difficult to prevent. Use of a stream of air entering through a capillary vitiates the results, ${ }^{1}$ so far as their value as vapor pressure measurements is concerned. Schmidt ${ }^{2}$ avoids bumping by placing a pad of cotton, saturated with the liquid, in the bottom of the flask. Regnault's difficulties and results in the case of mercury will be referred to later. ${ }^{3}$

Ramsay and Young sought to overcome the bumping and superheating difficulties, as well as the disadvantage of the large quantity of material required, and to avoid the need of a bath which could keep the apparatus at a constant and known temperature, by means of their wellknown method." In this, the liquid is allowed to trickle on to cotton enveloping the thermometer bulb. This bulb is situated in a flask surrounded by a bath, the temperature of which need not be constant or definitly known, but must be at least $20^{\circ}$ higher than that shown by the thermometer. When the pressure, which is read by means of a manometer in connection with the flask, is altered, the temperature as shown by the thermometer changes spontaneously to correspond. It will be seen that the thermometer readings are subject to the correction for the "compression coefficient," as noted by us in a former paper, ${ }^{5}$ although

1 For discussion of this, and of other sources of error, see No. II of this series, This JoURnal, 32, 9 I 1 .

2 Z. physik. Chem., 7, 440; 8, 628 .

$\therefore$ See No. IV of this series, following.

"Phil. Trans., 175, 37 (1884); J. Chem. Soc., 47, 42; Young, Stoichiometry, 140 Ostwald-Luther, [2] 177 .

- This Journat, 32, 905. The purpose of this paper, on "A Common Thermometric Error in the Determination of Boiling Points under Reduced Pressure," seems not to have been made sufficiently clear in the paper itself. Physicists have long been familiar with the "compression coefficient," although even some of them ignore 
this correction, amounting in certain cases to nearly $0.2^{\circ}$, is not mentioned in any of the published descriptions of the apparatus, or applied so far as we have seen, with a single exception, on any of the numerous occasions on which the method has been employed.

The error due to impurity is here to be looked for from the presence of air in the cotton wool and also, more especially, dissolved in the liquid. Fresh supplies of liquid with its dissolved "air" are constantly being introduced, nullifying any possibility of permanent expulsion by boiling out. The chief advantage of the simple dynamic method is thus lost, and the chief disadvantage of the static method is re-introduced. Should the liquid have acquired a non-volatil impurity, or contain by heredity an impurity less volatil than itself, it is plain that such impurity must gradually become more and more concentrated in the cotton surrounding the thermometer bulb. The method is not applicable to pressures much greater than atmospheric, or to liquids (e.g., mercury) which do not wet cotton, and is of questionable value for solids. ${ }^{1}$

\section{Section 3. The Apparatus.}

The special feature of the submerged-bulblet vapor pressure apparatus, already described, ${ }^{2}$ consists in the facility with which, using only a minute amount of the substance, the expulsion of dissolved and adhering impurities may be continued until constant values for the vapor pressure are secured. This important feature is precisely the one most conspicuously required to give trustworthiness to the static method and, as we have seen, most conspicuously lacking in the standard forms of apparatus working on the static principle. Now, while the bulblet method was being reduced to suitable form, we perceived that a modification of the apparatus would convert it into a static instrument. This static apparatus retained the advantages of the important feature referred to without loss of ease of manipulation, and possessed also several additional advantages over the regular static forms of apparatus. The simple bulblet was first changed by using a wider tube, instead of the capillary, and bending the lower end of the tube upwards. The whole had thus the form of a $C$, and an enlargement of the open end furnished a cup into which a confining liquid could be temporarily driven during the boiling-out process. The $\mathrm{C}$-formed apparatus was tied to the thermometer, just as was the simple bulblet. To allow further liberty in it in vapor pressure work. The paper dealt with the types of thermometers commonly employed by chemists, and with the considerable dilatations occurring when large intervals of pressure are concerned. The effects cannot be ignored in vacuum distillation and in vapor pressure determinations by the cotton-jacketed-thermometer method, for example, both of which are operations much used by chemists, and not hitherto associated in their minds with the necessity of employing this correction.

${ }^{1}$ See No. $\mathrm{V}$ of this series.

2 This JoURNAL, 32, 907 . 
the choice of a confining fluid, the open limb was next lengthened so as to extend above the surface of the bath. After a series of minor changes, the form described below was finally adopted.

It is necessary to describe the apparatus and the corrections used in minute detail, as only thus can the exact conditions be understood, and only thus can the data secured retain their value if, for example, sources of error which have escaped attention should subsequently be discovered.

The Isoteniscope, Bath, and Stirrer. -The substance is placed in the spherical bulb, which is about $20 \mathrm{~mm}$. in diameter (Fig. I). The confining liquid occupies the lower half of the U-tube, which

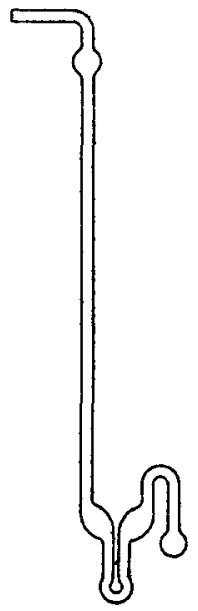

Fig. I. is $30-35 \mathrm{~mm}$. in height. The small bulbs on each limb of the U-tube prevent the ascent of the confining liquid (by suction) into the bulb or the vertical tube. For the sake of compactness, the spherical bulb is placed behind the U-tube, and not in the same plane with it as shown (for clearness) in the figure, the purpose of the apparatus being to show when two pressures have become equal, the arrangement may be called an isoteniscope. The present form, to distinguish it from a different one to be described in a later paper, may be called the static isoteniscope. A two-liter beaker of tall shape forms the bath. The vertical tube of the isoteniscope is about 24 $\mathrm{cm}$. long, so that the rubber connection is sufficiently far above the heated bath-liquid.

When the substance being studied is a liquid, the lower part of the U-tube is charged with this liquid itself. When the substance thus acts as its own confining liquid, it has the great advantage over mercury that its specific gravity is usually small. Hence, when the levels in both limbs of the U-tube appear to the eye to be identical, the error, when converted into mercury height, is negligible.

It is only when the vapor pressure of a non-fusing solid is being determined that the question of choosing a confining liquid comes up. The conditions to be fulfilled are that the confining liquid shall not have an appreciable vapor pressure of its own at the temperatures to be employed, and that the vapor of the substance shall not dissolve in it. A liquid which interacts chemically with the vapor of the substance should be avoided, especially if a gas is produced. But, as will be seen in the paper on the constitution of calomel vapor, a slow chemical action involving no gas production is not prohibitory. Among the suitable substances are mercury and melted paraffin at the lower temperatures, and fusible alloys or a molten salt or mixture of salts at high temperatures. In the 
case of solids, it is necessary to charge the bulb before fusing it to the U-tube.

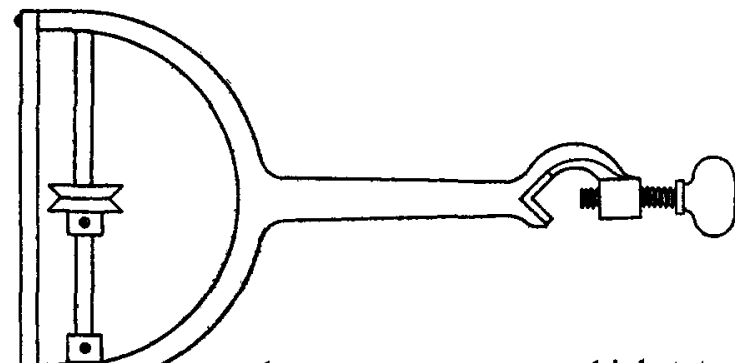

To permit sufficient immersion of the thermometer (platinum resistance, or mercury) in the bath-liquid, beakers over $23 \mathrm{~cm}$. high and II $\mathrm{cm}$. wide are used, and are filled almost to the brim. Beakers of Jena glass are necessary at high temperatures. The details in regard to bath liquids, and in regard to the handling of the beakers when a nitrate bath $i$ used, have already been given. ${ }^{1}$

The most essential part is to secure steadiness and equal distribution of the temperature. A cylinder of metal, or of glass (cut from a broken beaker), forms a necessary and sufficient jacket for the bath. The stirring apparatus, however, required especial attention. With stirring which was vigorous, and of the nature ordinarily considered satisfactory, perfectly constant pressures at a given temperature could not be obtained. In spite of the great heat capacity of the bath-liquid, slight inequalities in temperature between the substance and the thermometer arose. It appears that chemists are only beginning to realize that thermal equilibrium can be obtained only by the use of violent, almost riotous stirring. Richards ${ }^{2}$ has recently called attention to the same fact, in connection with his highly exact thermochemical measurements. We changed the form of our stirring apparatus (Fig. 2) repeatedly before a structure occupying a small area was secured which rotated with suffcient speed, and was so stiff of stem and so massive as to bearings and supports that it did not "whip" in the bath or produce too much noise. ${ }^{3}$ When these condiFig. 2. tions had been met, constant results, even with a resist-

1 This Journal, 32, 899 .

2Ibid., 3I, 1280 (I909).

3 The stirrer (Fig. 2) was made from an ordinary retort-stand ring. The rod (3 $\mathrm{mm}$. in diameter), driven rapidly by an electric motor, rotates in two holes bored in the ring, and is supported by a stout strip of brass (seen edgewise) which extends down almost to the first vane. The length from the lower side of the ring to the lowest vane is $28 \mathrm{~cm}$. The vanes are in sets of three, each set $25 \mathrm{~mm}$. in diameter. 
ance thermometer giving a large galvanometer deflection for one hundredth of a degree, were easily secured, where before they had seemed unattainable.

It is important to place the stirrer so that it may communicate some of its vibration to the substance (if a liquid) in the bulb. The resulting, constant agitation promotes the liberation of the vapor. It also prevents the limitation of the evaporation to the mere surface layer, a condition which would delay or prevent the complete elimination of dissolved gases.

By use of transparent quartz for the vaporizing vessel, and a quartz beaker, there is no reason why this method should not give exact determinations of vapor pressures and of dissociation pressures up to the softening point of quartz. Vapor pressures have not yet been measured accurately at such temperatures and, for dissociation pressures, the combination of a platinum heating chamber fused to a U-tube of glass, to render the confining liquid visible, ${ }^{1}$ has several disadvantages.

The Platinum Resistance Thermometer.-While a mercury thermometer may be used, the platinum resistance thermometer is, of course, a more exact and trustworthy instrument. Quite apart from this, however, the latter has a special advantage in work of this kind, where the complete expulsion of foreign matter is ascertained by repeated observations, made at exactly the same temperature. After a second boiling out and equalization of the pressures, the temperature of the bath itself can be readjusted until the spot of light occupies its precise former position. Thus, while the actual temperature may not be known with a greater accuracy than $\pm 0 . I^{\circ}$ or $\pm 0.01^{\circ}$, according to the precautions taken, this readjustment of the bath temperature may very easily be made with an error much smaller than these.

The platinum resistance thermometer employed was of the form devised by Haagen. ${ }^{2}$ In this form, the resistance wire is wound on a 6 $\mathrm{cm}$. length of quartz tube, of diameter somewhat over I $\mathrm{mm}$., which is then inserted into a very slightly wider quartz tube. The outer tube is then fused on to the inner one, thus embedding the resistance wire in quartz. The "bulb" so prepared is fused to a suitable length $(24 \mathrm{~cm}$.) of wider quartz tubing which carries the platinum and silver leads. There are no compensation leads.

For measuring resistance a Wheatstone bridge arrangement was used, with an arm ratio of Io to $\mathrm{I}$. The box resistances, of manganin, were calibrated, and the appropriate correction applied to all measurements made. The largest error of any of the single coils employed was 2.6 parts in ro,ooo. The coils were not maintained at constant temperature, but, in order that the temperature correction applied might be as small

' John Johnston, Z. physik. Chem., 62, 330 (Igo8).

$2 Z$. angew. Chem., 20, 565 . 
as possible, the temperature of the coils was kept close to that which they possessed when the fixed points were determined. The resistance of the thermometer was about 50 ohms at $0^{\circ}$. The measuring current varied from 3 milli-amperes at $0^{\circ}$ to $I .2$ at $445^{\circ}$. No correction for heating by the measuring current was required when the thermometer was immersed in water, fused nitrates, steam at $100^{\circ}$, or sulphur vapor at $445^{\circ}$. A small correction was necessary only when moistened ice, with its badly conducting, interstitial air spaces, surrounded the thermometer bulb. The sensitiveness of the galvanometer was such that a movement of the light spot of $\mathrm{I} \mathrm{cm}$. on the scale corresponded to $0.04^{\circ}$ at $0^{\circ}$ and to $0.08^{\circ}$ at $445^{\circ}$. The fixed points used were the freezing point of water, the boiling point of water and the boiling point of sulphur. The boiling point of sulphur was assumed, in accord with Holborn and Henning, ${ }^{1}$ at $445^{\circ}$. Its true value may lie closer to $444.9^{\circ}$ on the thermodynamic scale, ${ }^{2}$ but, as this datum is liable to be changed by future observations, it was thought better to adopt the rounder number. Obtaining the ice point and the water boiling point presents little difficulty, if the usual precautions are observed. As is well known, however, the boiling point of sulphur found varies considerably with the size of the apparatus and the screening, etc., adopted. ${ }^{3}$ We employed a gas-heated boiling tube of thin brass of $5.5 \mathrm{~cm}$. diameter and $47 \mathrm{~cm}$. length, jacketed by a thickness of $5^{-6} \mathrm{~cm}$. of asbestos packing. The bulb was protected by a cone of asbestos paper, closed below, whose base was situated ro-1 2 $\mathrm{cm}$. above the surface of the boiling sulphur and whose apex was $20 \mathrm{~cm}$. below the level of condensation. We were careful to employ the roll sulphur of commerce, and used a depth of about $8 \mathrm{~cm}$. Kahlbaum's crystallized sulphur contains volatile impurity. The reductions, for pressure, of the boiling points of sulphur and of water were made in accordance with the data of Holborn and Henning." As the constants of the platinum thermometer are known to be changed by prolonged heating, the fixed points were redetermined whenever the thermometer had been kept long at high temperatures. The following figures will give an idea of the degree of constancy of the thermometer used, and relate to an epoch when the thermometer was being heated at temperatures of $300^{\circ}-445^{\circ}$ for many consecutive hours: I909, October 8th, $R_{\circ}=50$. I 50 ohms; Oct. I 8 th, $R_{\circ}=50$. I 61 I Oct. $22 \mathrm{nd}, R_{\circ}=50.1170$. Here the total change amounts to $0.01^{\circ}$. The corresponding values of

: Ann. Physik, [3] 26, 833 (1908).

2 See Callendar and Moss, Proc. Roy. Soc. A, 83, 106 (1910); Waidner and Burgess, Bull. Bureau of Standards, 6, 149 (Nov., Igog).

' See Eumorfopoulos, Proc. Roy. Soc. A, 8I, 339 (1908); Waidner and Burgess, Loc. cit.

Loc. cit. 
the fundamental coefficient were $0.00386366,0.00386384,0.0038667 \mathrm{I}$. These values approach the value for the purest platinum (0.00389).

In reducing the results, the difference formula of Callendar was employed. The constant ò changed little from I. $6 \mathrm{I}_{47}$ (using $445^{\circ}$ as the boiling point of sulphur). If a lower value is assumed for the boiling point, the value of $\delta$ is smaller. With resistance wires of impure platinum the Callendar formula requires modification. ${ }^{1}$ To test the degree of its applicability to our wire and to ascertain whether, in the absence of compensation leads, correction was necessary for the change of resistance of the leads used, or for any other reason, two other standard temperatures were determined. Holborn and Henning ${ }^{2}$ have determined upon their temperature scale the boiling points of naphthalene and of benzophenone, and also the changes in these boiling points for small changes of pressure. Their values are $218.039^{\circ}$ and $306.081^{\circ}$, respectively; we found (a single observation) $218.075^{\circ}\left(\Delta=0.036^{\circ}\right)$, and (mean of the only two observations made) $306.089^{\circ}\left(\Delta=0.008^{\circ}\right)$, respectively. The correction to apply to the platinum temperature of our thermometer to obtain tijermodynamic temperature (b. p. of sulphur $445^{\circ}$ ) is at $218^{\circ}, 4.154^{\circ}$, while at temperatures between $0^{\circ}$ and $100^{\circ}$ this correction has a maximum value, at $5^{\circ}$, of $-0.404^{\circ}$. Our temperature measurements may, therefore, be considered accurate to $\pm 0 . \mathrm{r}^{\circ}$ in the range $250^{\circ}-435^{\circ}$ and to $\pm 0.01^{\circ}$ in the range $50^{\circ}-90^{\circ}$. It may be remarked that, should it seem desirable, our temperature scale may, from the data given, be readily reduced to correspond with any other boiling point of sulphur than that here adopted.

The Pressure Gage and Barometer.-The gage consisted of a glass tube of I I $\mathrm{mm}$. inside diameter, of which the open $\operatorname{limb}$ and that connected with the apparatus were, respectively, $2 \mathrm{~m}$. and $1.4 \mathrm{~m}$. long. The latter limb was provided with a stopcock. A long mirror behind the gage eliminated the effects of parallax.

The mercury heights were measured by means of a steel tape, the gradation of which was calibrated by comparison with a standard meter. From the results of this comparison, and the coefficients of expansion of the steel and of mercury, a table of corrections covering the whole range of the room temperatures was prepared.

The mercury heights were read by means of a fine, truly horizontal hair-line ruled on a strip of glass (a microscope slide), carried by a cursor or carriage. The cursor consisted of two spring collars of brass $(10 \mathrm{~cm}$. apart), connected together rigidly by a metal bar which carried a horizontal arm to support the microscope slide. The brass collars grasped a

${ }^{1}$ Callendar, Phil. Mag. [5], 47, 19I (1899); Tory, Ibid., 50, 42I (19oo); Waidner and Burgess, Loc. cit.

${ }^{2}$ Loc. cit. 
mandril-drawn, seamless steel tube, $18 \mathrm{~mm}$. in diameter and over $2 \mathrm{~m}$. in length, which was fixed in a truly vertical position. This steel tube, along with the steel tape, gage, and mirror were attached to a long board, which was suspended by a rope and balanced by a counterweight. The whole gage could thus be moved vertically between guides, in such a way as to bring to the level of the eye the point at which the mercury stood. This kept the mercury accessible to convenient observation during the numerous manipulations connected with a reading. By the use of the cursor described above the somewhat tedious use of a cathetometer was avoided, with no sacrifice of accuracy.

The heated air arising from the bath passed directly into the flues of a draught cupboard, within which the bath stood, and did not reach the gage, which was outside the cupboard. Moreover, the gage was shielded from heat radiated by the bath.

Pure mercury from the laboratory supply was redistilled in vacuo before use in the gage, and was tested by the method of Hulett and Minchin. ${ }^{1}$ A portion was redistilled twice in air to oxidize the more electropositive metals, if present. The potential difference between the two samples, when placed in $N \mathrm{KCl}$ solution saturated with calomel, was less than 0.000003 volt. The metal was, therefore, of a satisfactory degree of purity.

Since an open gage was used, the barometric height had to be read. The instrument was one made by Henry Green, of Brooklyn. The scale was already corrected for capillarity. The instrument was standardized by comparison with a barometer, in which the tube was exhausted by means of a mercury pump until the McLeod gage showed a residual pressure of less than $0.003 \mathrm{~mm}$. The reading of the Green barometer was found to be correct.

The following corrections were applied to the pressures:

I. The pressures were reduced to $\mathrm{mm}$. of mercury at $0^{\circ}$. For this purpose five carefully compared thermometers, graduated to tenths of a degree, were suspended at intervals along the gage. To eliminate differences in mass and lag between the thermometers and the mercury in the gage, the bulbs of the thermometers were immersed in mercury contained in tubes of the same diameter as the gage. The coefficient of linear expansion of mercury used was 0.0001818 . The error in density of mercury due to its compressibility is negligible at the pressures employed.

2. The coefficient of linear expansion of steel used in calibrating the steel tape was $0.0000 \mathrm{II}$.

3. The mercury heights were reduced to the sea level at $45^{\circ} \mathrm{N}$. L. The value of the gravity constant, $g$, determined in the Ryerson Physical

${ }^{1}$ Physic. Rev., 21, 388 (1905). 
Laboratory of the University, namely 980.34 , agrees precisely with that calculated from latitude and elevation. The value of $g$ taken as the standard $^{1}$ was $980.665 \mathrm{~cm}$. sec. ${ }^{-2}$, and the factor by which the observed heights were multiplied was therefore 0.99971 . The amount of this correction is thus $0.25 \mathrm{~mm}$. per $760 \mathrm{~mm}$.

4. In measuring the vapor pressures of water, since the temperature error in that case was less than $\pm 0.01^{\circ}$, suitable correction was made for the difference in level between the cistern of the barometer and the mercury in the open limb of the gage. A similar correction was made, when necessary, for the difference in level between the surface of the water in the bulb of the isoteniscope and the surface of the mercury in the closed limb of the gage. The amount of this correction is about $0.09 \mathrm{~mm}$. per meter head of air.

Other Parts of the Apparatus.-The general arrangement of the apparatus is shown in Fig. 3, which is diagrammatic. The isoteniscope and the gage were connected with a large iron bottle. Another piece of tubing leading from the bottle gave connections, by means of T-tubes, with (I) the atmosphere, (2) a vacuum reservoir and water pump, (3) a pressure reservoir, and compression pump. A stopcock on the first, and screw clamps on each of the other two tubes permitted any one to be used at will. The rubber tubing leading to the atmosphere was so long that it hung out over the edge of the base of the draft cupboard.

The water pump, with its residual pressure of about $20 \mathrm{~mm}$., according to the temperature of the water, served our purpose very well, as no measurements of vapor pressures below $80 \mathrm{~mm}$. were to be made. With a mercury pump, much lower vapor pressures could be studicd with the same arrangement of the rest of the apparatus.

The connections were made with thick-walled rubber tubing, wired at all junctions, and coated heavily with a suitable composition. No tendency to leakage was ever observed.

The Manipulation.--The following statements apply particularly to the determinations of the vapor pressures of water below one atmosphere. The modifications required when pressures over one atmosphere are measured, or when another liquid or a solid is used, will be understood without special description.

When the temperature has reached the desired point, and has become constant, the exit to the suction bottle and pump is opened and remains open until the pressure in the iron bottle has been reduced to such a point that the water in the bulb boils, and the vapor passes freely through the confining fluid (itself also water) in the U-tube. The confining fluid is driven into the remote side of the U-tube and the bulb above it. When

${ }^{1}$ Troisième conf. gén. des poids et mésures, I90I, 66, 68. 


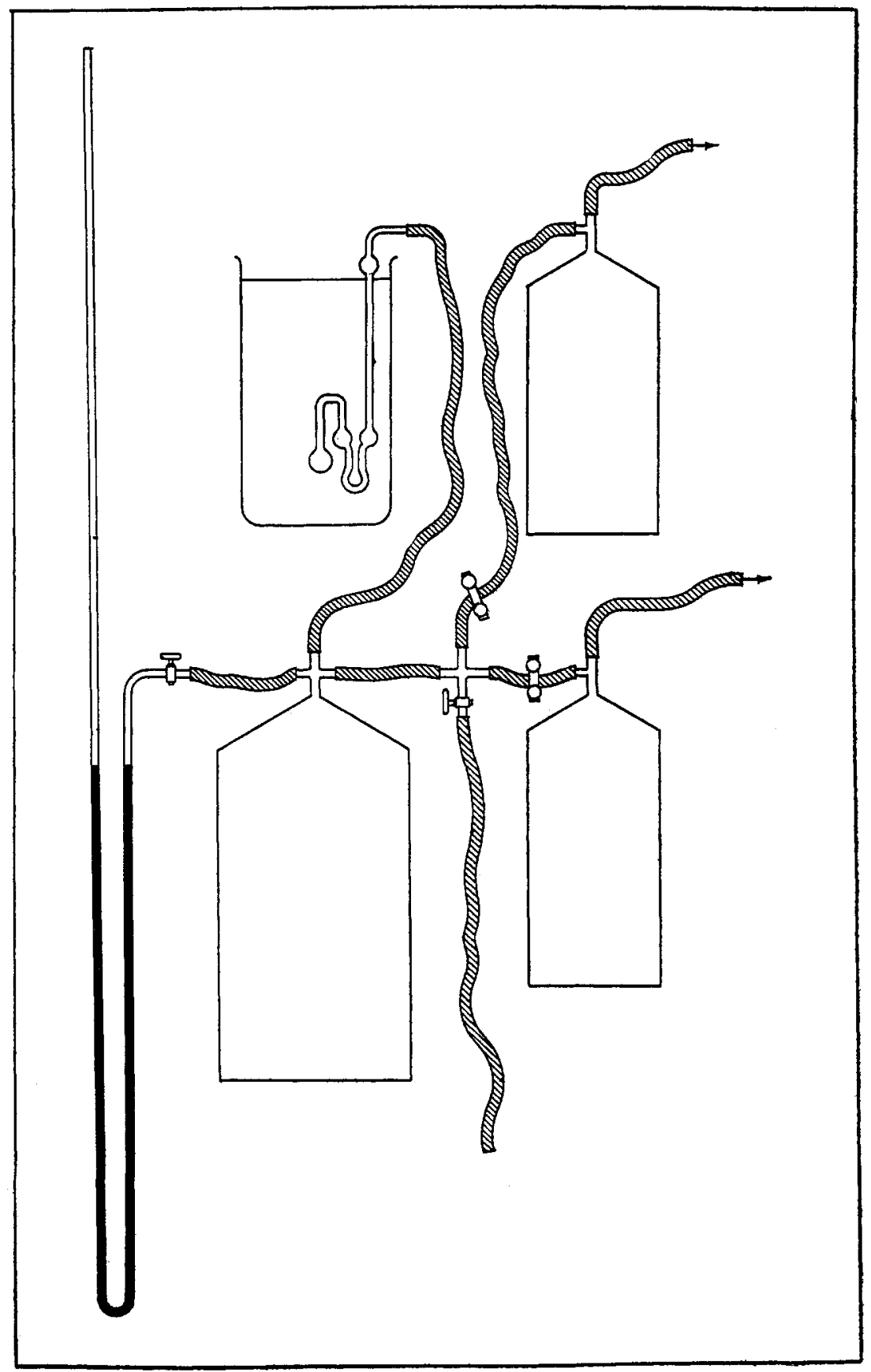

Fig. 3 . 
the air in the bulb, and the gases adhering to the bulb and dissolved in the water have been driven out, air is cautiously admitted to the iron bottle through the exit to the atmosphere until the levels of the water in both limbs of the $L$-tube are identical. On account of the cooling of the substance in the bulb by evaporation, equilibrium is not reached at once, so that the adjustment has to be repeated until the levels in the U-tube remain constant. The finer adjustment is not easy to manage by the use of the stopcock alone, and the long rubber tube opening to the air is employed. When, for example, a slight increase in pressure is required, the tube is grasped with the hands at two places and air is admitted to the bottle in small portions at a time until equilibrium is attained.

When the adjustment has been perfected, the stopcock on the gage is closed, the temperature reading is confirmed, and the gage and barometer are read. Within the time required for making the gage reading, no variation occurred in the level of the mercury due to a change in temperature in the air confined in the closed limb. To make sure that volatil foreign matter or gas has all been expelled, the whole process of boiling out, adjusting, and reading is repeated until constant values are obtained.

The temperature of the bath is then raised, and a new observation taken. Unless the substance is unstable, and decomposition products arise, repeated boilings at the second and higher temperatures produce no change in the values first obtained.

\section{Section 4. Criticism of the Method.}

It will be seen that the isoteniscope is free from the sources of error which affect the older forms of apparatus for determining vapor pressures. For example:

I. The isoteniscope substitutes for mercury a confining fluid of low specific gravity and thus eliminates the error in leveling involved in some static methods.

2. The apparatus dethrones mercury from its position as sole confining fluid, and substitutes a wide choice of liquids. In consequence, all errors due to the volatility of a foreign confining fluid, and to solubility of the substance in, or interaction of, the substance with such a confining fluid disappear entirely.

3. By being adapted to use in a liquid bath (with violent stirring), the apparatus reduces to a minimum all errors due to unsteadiness of the temperature, and to inequality in the temperatures of the substance, its vapor, and the thermometer.

4. By providing a simple method for expelling air bubbles and adhering and dissolved gases, and for repeating the expulsion until the success of the operation is demonstrated, the isoteniscope removes a source of 
error (and of total uncertainty as to the amount of that error) which destroys all confidence in the exactness of the results obtained by the older static methods.

5. By permitting the making of an extended series of observations without using more than half of the sample, the apparatus obviates an error due to concentration of involatil impurities in the residue which affects some dynamic methods.

6. By allowing the expulsion of accumulated gas immediately before a reading, the apparatus makes possible accurate measurements with many substances which decompose slowly to give a permanent gas. By the older static methods, accurate measurements in such cases was necessarily impossible.

Aside from this avoidance of certain sources of error, the apparatus possesses some noteworthy advantages:

I. A small amount of material suffices (usually less than I gram).

2. The filling of the apparatus, and the manipulations involved in a measurement, are incomparably simpler than any other static method.

3. The correction for dilatation of the bulb of the mercury thermomter (the so-called "pressure" coefficient), which some dynamic methods involve, is avoided.

4. Since, with liquids, no foreign substance (such as mercury) is present, the method permits measurements with all reasonably stable liquids, no matter how active, chemically, they may be.

5. The method is applicable to all solids, provided a non-interacting, non-solvent, non-volatil confining liquid can be found. When such a liquid cannot be found, a dynamic method to be described in a later paper ("Studies in Vapor Pressure, V") may be used.

\section{Section 5. The Vapor Pressures of Water.}

On account of the facts about water, some of which were brought out in Section I, namely the ease with which natural impurities are removed, the relatively slight solubilities of gases in water, the more normal behavior of water as shown in the work of Tammann and of Wüllner and Grotian, and the relatively slight inconsistencies in the existing determinations of its vapor pressures, water is a suitable substance for affording a test of the merits of the method. Moreover, no other substance combines all these qualities, and water is therefore at present the only suitable substance.

There is no reason why mercury should not equal, or even excel, water in freedom from impurities and in regularity of behavior. Only the inconsistencies in the measurements which thus far have been made, and especially the utter disagreement of those above the boiling point, render it unsuitable for comparing methods. 
Results.-The isoteniscope was thoroughly steamed out, and distilled water, giving no appreciable residue on evaporation, was redistilled into it. The method itself prorides for the expulsion of dissolved gases. The measurements were made with the apparatus described above, and the corrections before mentioned were applied.

The observations were made by design as close as possible to temperatures, the values of which should be represented by whole numbers. The differences for one-tenth of a degree at each temperature, taken from Eckholm's ${ }^{1}$ tables, were then used in making the very small adjustments required to reduce each observation to the nearest whole number of degrees. The results of this operation are given in the following table (I) under S \& M. The pressures in this column, therefore, are not smoothed results, such as may be obtained by graphical or other methods, but are essentially actual observations, subject to the irregularities which individual observations usually show. This enables them to afford the most rigorous test of the method, while the adjustment facilitates the comparison with the data of other observers, which are usually given for whole degrees. The twenty-seven observations give, after adjustment, values at eleven different temperatures.

\begin{tabular}{|c|c|c|c|}
\hline & $5 \& I$ & & ABLE I. \\
\hline$t$ & No, of obsus. & $p$ & $\mathrm{H} \& \mathrm{H}$. \\
\hline $50^{\circ}$ & 3 & 92.27 & $92 \cdot 30$ \\
\hline $5^{\mathrm{I}}$ & 4 & 97.03 & 96.99 \\
\hline 55 & I & $\mathrm{II} 7.87$ & I 17.85 \\
\hline 60 & 2 & $I_{49} . I_{3}$ & 149.19 \\
\hline 65 & 3 & I87. I9 & $187 \cdot 36$ \\
\hline 70 & 3 & $233 \cdot 44$ & $233 \cdot 53$ \\
\hline 75 & $I$ & 288.78 & 289.0 \\
\hline 80 & I & $354 \cdot 90$ & $355 \cdot I$ \\
\hline 85 & 3 & $433 \cdot 54$ & $433 \cdot 5$ \\
\hline 89 & 5 & 505.87 & 506.1 \\
\hline 90 & I & $525 \cdot 94$ & 525.8 \\
\hline
\end{tabular}

\begin{tabular}{cc} 
Differences, H \& H-S \& M. & Degrees. \\
\hline $\mathrm{mm}$. & -0.006 \\
+0.03 & +0.009 \\
-0.04 & +0.004 \\
-0.02 & -0.010 \\
+0.06 & -0.019 \\
+0.17 & -0.009 \\
+0.09 & -0.018 \\
+0.22 & -0.014 \\
+0.20 & +0.002 \\
-0.04 & -0.011 \\
+0.23 & -0.007 \\
-0.14 &
\end{tabular}

For comparison, we give under $\mathrm{H} \& \mathrm{H}$ the corresponding values found by Holborn and Henning ${ }^{2}$ in the Reichsanstalt. These are undoubtedly the most accurate in existence. Their temperature scale is the same as ours. Their results are smoothed values, derived from numerous observations. The greatest divergencies are $0.23 \mathrm{~mm}$. and $0.019^{\circ}$. The algebraic sum of all the temperature differences, divided by the whole number of our observations (27), gives the mean divergence from $\mathrm{H} \&$ H's curve of a curve drawn through our observations. This mean di-

${ }^{1}$ Svensk. Vet. Akad., Arkiv. för Math., Astron., och Fysik, Band 4, Häfte 2, No. 29 ( 1908$)$.

2. Ann. Physik, [4] 26, 833 (1908). The reason for accepting these values as the most accurate will be apparent to any one who considers the details of the method used 
vergence is $-0.0063^{\circ}$, which is well within the error which we assign to our measurement of absolute temperature $\left( \pm 0.01^{\circ}\right)$. The corresponding mean pressure deviation is $+0.08 \mathrm{~mm}$. This agreement is of especial interest since our method is static, while theirs was dynamic.

Comparison of Other Methods. - We may now institute a comparison between the results obtained by our method and those obtained by others, using Holborn and Henning's values as the standard of comparison.

Taking first the static methods, with which ours may most justly be compared, there are only two sets which included the region $50^{\circ}-90^{\circ}$, namely those of Magnus and of Batelli. In both cases mercury was the confining fluid, and the U-tube form of vaporizing vessel was used. Magnus ${ }^{1}$ boiled the mercury "well" after its introduction. He also boiled the water for $\mathrm{I} / 2-3 / 4$ hour, and then introduced it, while yet warm, through the open limb, by inclining the apparatus. Batelli" "caused the mercury to boil several times." The water was introduced in a small glass bottle, after elaborate purification and subsequent boiling for twentyfour hours. No precautions to remove gases adhering to the small bottles are mentioned.

In the first two columns of the following table (Table II), only the differences between the pressure values of Holborn and Henning and those of Magnus (M) and of Battelli (Ba), respectively, are given. These numbers are to be added to the published data, to give those of $\mathrm{H} \& \mathrm{H}$. The other columns will be explained presently:

TABLE II.

(Differences from $\mathrm{H} \& \mathrm{H}$.)

\begin{tabular}{|c|c|c|c|c|c|c|c|}
\hline \multirow[b]{2}{*}{$t$} & \multicolumn{2}{|c|}{ Static. } & \multicolumn{2}{|c|}{ Dynamic. } & \multicolumn{3}{|c|}{ Recalculations. } \\
\hline & M. & $\mathrm{Ba}$. & Rg. & w. & Br. & T. & E. \\
\hline $50^{\circ}$ & +0.33 & +1.85 & +0.28 & $\ldots$ & +0.32 & -0.22 & -0.34 \\
\hline 60 & +0.61 & $+2 \cdot 3$ & +0.36 & $\ldots$ & $+0.3 I$ & -0.19 & -0.38 \\
\hline 70 & +0.92 & $+2 \cdot 7$ & +0.58 & $\ldots$ & +0.22 & -0.14 & -0.40 \\
\hline 80 & $+\mathrm{I} .2$ & +2.7 & +0.5 & -0.3 & +0.2 & 0.0 & -0.34 \\
\hline 90 & $+I .0$ & $+2 . I$ & +0.3 & -0.2 & +0.3 & 0.0 & -0.2 \\
\hline Av. & $+0.8 I$ & $+2 \cdot 3$ & +0.4 & -0.25 & +0.27 & -O.II & \\
\hline
\end{tabular}

The average divergencies from $\mathrm{H} \& \mathrm{H}$ are: Magnus $+0.8 \mathrm{I} \mathrm{mm}$. (or $-0.07^{\circ}$ ), Batelli $+2.3 \mathrm{~mm}$. These are respectively ten and thirty times as great as our average divergence. It must be noted that the data of these two observers are all smoothed values.

Schell and Heuse $^{3}$ have recently determined the value at $50^{\circ}(92.54$ mm.) by a static method. Our value (static) confirms that of $\mathrm{H} \& \mathrm{H}$.

1 Pogg. Ann., 6r, 225 (1844).

'Ann. chim. phys., [6] 26, 410 (1892); [7] 3, 408 (1894).

Ann. Physik, [4] 3I, 7I5. 
On account of the extensive use which has been made of Ramsay and Young's static methods, both by themselves and by others, a comparison would be very instructive. Their barometer tube method, available up to nearly $760 \mathrm{~mm}$., with the special device for filling so as to exclude foreign gases, was not applied to water, which is the only suitable substance for making a rigid comparison. Their only determinations with water ${ }^{1}$ begin at $120^{\circ}$, and are therefore not directly comparable with ours. The filling of the tube' involved boiling of the substance, but not of the mercury in the tube. The differences between their values and those of $\mathrm{H} \& \mathrm{H}$ at their lowest temperatures are as follows: $120^{\circ},+4.9$; $130^{\circ},+6.6 ; 140^{\circ},+15.5 ; 150^{\circ},+0.7$. The average divergence is $+6.9 \mathrm{~mm} .$, or $-0.1^{\circ}$, and is of the same order as that of Magnus. These, again, are smoothed values. This divergence is not due to the difference between the scales of temperature used by Ramsay and Young (const.-vol. air-therm.) and by $\mathrm{H} \& \mathrm{H}$, for this would not exceed $0.014^{\circ}$ (corresponding to $\mathrm{I} .3 \mathrm{~mm}$.) even at $15 \mathrm{O}^{\circ}$, and besides, if taken into account, would increase the divergence.

If we turn now to results obtained by dynamic methods, there are only three sets which include the region under consideration, namely those of Regnault, Wiebe $\left(82^{\circ}-100^{\circ}\right)$, and Holborn and Henning. Regnault's ${ }^{3}$ dynamic observations extended from $43^{\circ}$ to $230^{\circ}$. In the column headed $\mathrm{Rg}$ of the foregoing Table II, we give the differences between the data of $\mathrm{H} \& \mathrm{H}$ and of Regnault, using for the latter the data calculated by the " $H$ " formula. This was the formula which Regnault found most generally satisfactory, and it appears to be especially $\mathrm{so}$ within the region in question. Wiebe made measurements from $82^{\circ}$ to $100^{\circ}$ only. His results (Col. W), however, seem to be considered especially good by $\mathrm{H} \& \mathrm{H}$, and they are weighted very heavily in Eckholm's recalculation of the data which he considered. The average divergences from the results of $\mathrm{H} \& \mathrm{H}$ are: Regnault, $\div 0.4 \mathrm{~mm}$. (or $-0.04^{\circ}$ ), and Wiebe $-0.25 \mathrm{~mm}$.

On account of the very large number of measurements made by Ramsay and Young, and by other observers, with their dynamic method, in which the thermometer bulb is surrounded by cotton saturated with the substance, a comparison of its performance with that of other methods is extremely desirable. Unfortunately, although they made a series of observations with water, ${ }^{8}$ they give no results and content themselves with stating that the values were "identical with those of Regnault."

${ }^{1}$ Phil. Trans., $A, \mathrm{I} 83, \mathrm{I0} 7$ (1892).

${ }^{2}$ Ibid., A, 178, 57 (1886); Young, Stoichionetry, I34 (1908).

${ }^{3}$ Rel. des Experiences, I, 465 ( 1847 ).

4 Z. Instrumentenkunde, 13, 329 (I893).

'See Section 2 of this paper.

- Phil. Trans, , r75, 48 (1884). 
It is a pity that they did not state more exactly the degree of approximation, and specify which of the appreciably divergent sets of data were used in the comparison-for example, the curve, the values calculated by "formula H" (those most commonly quoted, e.g., in the Chemiker Kalendar and Van Nostrand's Chemical Annual), or Brock's recalculation (adopted by Ostwald in his Handb.). As we have seen, however, the method is open to serious criticism.

Finally, in the last three columns (Table II) we give the results of Reg. nault, as recalculated by Brock $(\mathrm{Br})$, the data of all previous observers as combined and recalculated by Thiesen ${ }^{1}(T)$, which were adopted without change up to $100^{\circ}$ by Henning ${ }^{2}$ in his most vigorous study of the same data, and the results of Eckholm's (E) recalculation of the same data. As before, only the differences, $\mathrm{H} \& \mathrm{H}-\mathrm{Br}$, etc., appear.

This comparison shows that, assuming Holborn and Henning's values to be correct, the results by our method lie much closer to the true value than do those by any other static method. They likewise diverge much less than do the results of the recalculations of previous determinations. They lie also much closer than do the values obtained by the dynamic methods, although all writers are agreed that the dynamic methods give more trustworthy results than do the static ones which have hitherto been employed. ${ }^{3}$

The degree of self-consistency of the observations may be seen by inspection of Table I. A more detailed study of the deviations from a smooth curve of the individual observations obtained by this method will be undertaken in the following paper on mercury.

To determin definitly the merits of the isoteniscope, per se, it would be necessary to eliminate from the older observations the effects of the errors in the measurements of temperature and of pressure, and to isolate the error due to the form of the vaporizing chamber and the method of handling the substance. It is unfortunately impossible to do this. It is to be noted, however, that the gage and thermometer errors are common to static and dynamic methods, and should be essentially alike in both. Now the average magnitude of the divergencies of the dynamic and static methods, respectively, from that of $\mathrm{H} \& \mathrm{H}$ are $0.33 \mathrm{~mm}$. and

:Ann. Physik, [3] 67, 692 (1899).

2Ibid., [4] 22, 609 (1907). This was before the redetermination by Holborn and Henning.

s The much closer approximation of our results to those of $\mathrm{H} \& \mathrm{H}$ is not due to the fact that the same scale of temperature was used by both, whereas the other observers used air thermometers (Regnault, a mercury thermometer). The difference between the scales at $50^{\circ}-90^{\circ}$, except possibly in the case of Regnault's values, is so small that it would equal only a fraction of the divergence in each case, and besides, wherever the differences in pressure are positive in the preceding tables, an adjustment to the thermodynamic scale would only increase the divergencies. 
I. $55 \mathrm{~mm}$. The excess of the static over the dynamic may perhaps be held roughly to represent the minimum value of the error of the older static methods per se. Now this difference is $1.22 \mathrm{~mm}$., or about fifteen times the total divergence of our results due to all causes.

[Contribution from the Iaboratories of General and Physical Chemistry of THE UNIVERSITY OF CHICAGo.]

\section{STUDIES IN VAPOR PRESSURE: IV. A REDETERMINATION OF THE VAPOR PRESSURES OF MERCURY FROM $250^{\circ}$ TO $435^{\circ}$.}

By ALEXANDER SMITH AND ALAN W. C. MENZIES.

Received August 20, IgIO.

Both for practical and theoretical purposes, an exact knowledge of the physical constants, and particularly of the vapor pressures of mercury, is of the greatest importance. Mercury is used in innumerable ways in research and in many instances the accuracy of the results depends on a knowledge of the vapor pressures of this substance. Since mercury shows no evidence of a tendency to association, and since its vapor is monatomic, presenting in the former respect a great contrast to water, and in the latter respect even to the liquids of more normal behavior, like benzene, an exact knowledge of its vapor pressures should be of the utmost value in the study of the laws pertaining to vaporization. The relations, for example, between temperature and pressure and between these two and heat of vaporization, on account of the absence of complicating factors, should be of special simplicity in the case of mercury. Moreover, it is more easily obtained in a state of extreme purity than almost any other substance. Yet, in spite of all this, as Laby says, "the greatest-and it should be added, unnecessary-disagreement is to be found in the current values of this vapor pressure." For these reasons, and because accurate data were required for a study of calomel vapor which will shortly be published, a redetermination of the vapor pressures from $25^{\circ}$ to $435^{\circ}$ was undertaken. The range chosen was limited to the region required for this special purpose, but we intend later, with a longer gage, to extend the series. The theoretical study of our results is postponed until the longer series shall be available.

Previous Determinations.--The work of previous observers has been subjected to a critical study and their data have been combined by Laby. ${ }^{1}$ We are not concerned with the values at low temperatures, of which those of Pfaundler, ${ }^{2}$ Morley, ${ }^{3}$ and Hertz ${ }^{4}$ (the latter's extend to $207^{\circ}$ ) are in excellent agreement, and are irreconcilable with the erratic values of

${ }^{1}$ Phil. Mag., [6] I6, 789 (1908).

2 Ann. Physik, [3] 63, 36 (I897).

${ }^{3}$ Phil. Mag., [6] 7, 662 (1904).

${ }^{4}$ Ann. Physik, [3] I7, 193 (1882) 